\title{
De lo oculto que se les permite y de la visibilidad que se les niega: las mujeres en las letras y artes de Cartagena de Indias (1940-1949) ${ }^{*_{1}}$
}

\author{
Gloria Bonilla Vélez ${ }^{2}$ \\ Raúl A. Cera Ochoa \\ Carlos M. Castrillón Castro \\ Nathaly Ortega Polanco ${ }^{3}$ \\ Universidad de Cartagena
}

\section{Resumen}

En el siguiente artículo nos proponemos abordar cómo, a través del cultivo de las letras y las artes, algunas mujeres de la élite cartagenera en la década del cuarenta, intentaron generar una crítica sobre su precaria condición educativa motivada por restricciones de género-, al tiempo que buscaban ser visibles ante una sociedad que las excluía de lo público y les atribuía roles nítidamente diferenciados del masculino. Para ello haremos

\section{Abstract}

In the following article, we aim to explore how in Cartagena during the 1940s, some upper-class women, motivated by gender restrictions, attempted to criticize their educational situation through their involvement in the arts. Furthermore, through this involvement, these women looked to be visible in a society that marginalized them through specific gender roles different from those of men. For that reason we are going to make an ex-

\footnotetext{
* From their permitted hiding and their denied visibility: women in literature and the arts in Cartagena (1940-1949).

Recibido: Marzo, 2011 - Aprobado: Julio, 2011.

${ }^{1}$ Este artículo es de tipo reflexivo, y cabe destacar la utilización, para su desarrollo, de la perspectiva de género. Cuando hablamos de "perspectiva de género", nos referimos a un enfoque de análisis de la realidad para interpretar las relaciones de poder que existen entre hombres y mujeres. Se trata de "otra mirada" que contempla un mundo no hecho sólo a medida de hombres, sino un mundo donde las mujeres se hacen visibles con sus realidades, sus aspiraciones y sus capacidades.

${ }^{2}$ Docente del Programa de Historia de la Universidad de Cartagena. Historiadora de la Universidad de Antioquia. Doctora Summa Cum Laude de la Universidad Pablo de Olavide (Sevilla, España). Miembro de los Grupos de Investigación "Frontera, sociedad y cultura en América Latina y el Caribe" y "Estudios de familia, masculinidades y feminidades". e-mail: gloesbo1810@gmail.com

${ }^{3}$ Historiadores de la Universidad de Cartagena. Miembros del Grupo de Investigación Estudios de Familias, Masculinidades y Feminidades de la facultad de Ciencias Sociales y Educación de la Universidad de Cartagena.
} 
un recorrido sobre los antecedentes históricos y algunos debates presentados en la prensa sobre el papel de la mujer en relación con las letras y las artes.

Palabras clave: mujer, lo público, género, artes, letras. pedition in his historical antecedent, some of the debates in press about the role of the women in relation with the literature and art.

Key words: woman, public, gender, arts, letters.

\section{Introducción}

La presencia de las mujeres en el campo de las letras y de las artes en Colombia es cada vez más relevante, pero al examinar el panorama de siglos anteriores advertimos una realidad muy distinta, pues la posibilidad de participar en lo público, por medio del cultivo literario, periodístico o artístico, era reducida para las mujeres, y aquellas que lograban romper el cerco se debían acoger a la sombra de un marido, un hermano o un padre. "Lo público" es entendido en este ensayo como el santuario que ocupan los hombres y que se opone a "lo privado", a lo doméstico (el lugar que, según la tradición patriarcal, corresponde a las mujeres).

Durante mucho tiempo se relacionó al hogar y la familia como el resultado de las actividades productivas de cada género. En la división sexual del trabajo las mujeres fueron colocadas en la casa para cocinar, limpiar y cuidar a los hijos, mientras que los hombres participaban de las actitudes desarrolladas fuera del hogar, como las relativas a la producción de bienes y a la política. Autores como Postor (1998: 227) han señalado que lo privado fue visto como lo domestico, lo personal, lo natural, la intimidad, la reproducción, la inmanencia y el cuidado; en cambio lo público aparece como lo abstracto, lo cultural, lo radical, el ejercicio de la ciudadanía y la producción. De ahí que la identificación de lo privado con lo doméstico sea utilizado para preservar y reproducir la relaciones de dominación entre hombres y mujeres ${ }^{4}$.

Hacer un estudio sobre la incursión de las mujeres en el campo de las letras y las artes en un contexto como el de Cartagena en la década del cuarenta constituye un verdadero reto: la historiografía

\footnotetext{
${ }^{4}$ La historiadora francesa Michelle Perrot (2003) señala que "lo público" posee una dimensión física o material. Es decir, la ciudad con sus calles, plazas y los lugares de recreación. Y otra dimensión intangible, o espiritual, donde se encuentran los referentes simbólicos, representaciones o las nociones éticas como los derechos y deberes que dibujan una ciudadanía.
} 
regional, durante algún tiempo, ha dejado a las mujeres por fuera de los diferentes procesos históricos de participación, ya sean políticos, económicos, sociales o culturales. Hasta hace algunas décadas, sin embargo, se ha dado un gran interés, por parte de los investigadores, en reivindicar el papel de las mujeres en la participación de procesos de ciudadanía. Quienes han venido adelantando estos estudios buscan visibilizar y reivindicar hechos representativos en que las mujeres se han vinculado junto con los hombres en la historia regional.

Lo que se ha impulsando en esta materia se debe a las afirmaciones teóricas y metodológicas de la Escuela de los Annales, que aportó a los tradicionales temas -económicos y políticos- el estudio de las mentalidades, centrados en lo cotidiano, lo privado y lo individual. Pero sobre todo, fue el movimiento de las mujeres el que las ha llevado al escenario de la historia, con ciertos interrogantes acerca de su pasado y de su futuro (Duby \& Perrot, 1992: 113). El diálogo con otras disciplinas como la sociología, la antropología, la psicología, o la lingüística, han contribuido en las diferentes aproximaciones sociales, dando como resultado nuevos objetos de reflexión. Para Lagunas (1996: 47), estos nuevos objetos de observación se han convertido en campo especifico de la historia social, que es la encargada de llevar a cabo reflexiones sobre las diferentes actividades que están por fuera de las acciones heroicas y que integran a actores invisibilizados.

No obstante, las producciones historiográficas que resaltan las participaciones de las mujeres en las letras y en las artes siguen siendo insuficientes para el caso de la historiografía local. Pero es importante resaltar los trabajos investigativos de corte general que se han hecho en el país, como el de Patricia Londoño (1990): Publicaciones periódicas dirigidas a la mujer en Colombia, 1858-1930. En este trabajo la autora plantea cómo se pretendía lograr desde la prensa una educación sobre las necesidades sociales de las mujeres. El propósito de estas publicaciones era entretener y cultiva al sexo femenino. En Mujeres en la literatura del siglo XIX, de Jan María Dejong (1995), se describe, por ejemplo, el caso de algunas mujeres de élite que sobresalieron en el mundo literario, pero de las cuales se desconoce su verdadera identidad, a causa de los seudónimos que utilizaron.

El ensayo de María Mercedes Jaramillo y Betty Osorio De Negrete (1995), Escritoras Colombianas del Siglo XX, nos permite señalar y entender la ruta que hace visible el trabajo de las mujeres en la cultura (siendo algunas privilegiadas por su educación, recursos y tiempo necesario se dedicaron a la labor literaria). Y si bien en estos 
trabajos se refleja una dinámica a nivel nacional, se deja entrever la participación de mujeres cartageneras, convirtiéndose en gran ayuda para el desarrollo de nuestro trabajo: un estudio -desde la prensa cartagenera (periódicos como El Fígaro y El Universal)- sobre el papel de las mujeres intelectuales de la década del cuarenta, teniendo en cuenta aspectos como el lugar, representación, condición, su palabra y participación, y el papel que ejercieron en el mundo de las letras y las artes. Al mismo tiempo, reflexionaremos sobre aquellas mujeres que intentaron generar una crítica sobre su precaria condición educativa determinada por las restricciones de género.

\section{De la correspondencia familiar a ensayos y poemas: las mujeres en Colombia hacia su encuentro con las letras}

Escribir no fue fácil para las mujeres. Durante la época colonial, y más tarde durante la Independencia, y entrada la primera mitad del siglo XIX, su escritura estuvo limitada al espacio privado y al correo familiar. Es allí, según Vidales (2012: 3), donde encontramos las primeras piezas de una literatura femenina auténticamente nacional: con frecuencia esposas, novias, hermanas, primas y sobrinas informaban sobre diversos temas a parientes que se encontraban presos, perseguidos o desterrados por cuestionar ideológicamente el sistema de dominación español y los valores tradicionales. El estado político de su provincia o región, el estado de ánimo de la población y las medidas represivas tomadas por el régimen contra las nuevas ideas eran algunos de los temas a tratar en la correspondencia ${ }^{5}$.

Para que las mujeres pudieran explorar y ejercer el quehacer literario, más allá de la correspondencia familiar, incidieron algunas situaciones, entre ellas la pertenencia a familias de élite con una tradición literaria que, por un lado, les ofrecía los recursos para su publicación, y por otro, cierto nivel educativo. Para este grupo, generalmente de escritoras, la educación era la frontera entre la subordinación y la liberación (Luna \& Villarreal, 1994: 67). Sirva de ilustración el caso de Josefa Acevedo de Gómez, primera poetisa, escritora moralista y de costumbres, nacida en Bogotá el 23 enero de 1803 y muerta en Pasca, el 19 enero de 1861. En la época republicana, Acevedo rompió el prolongado silencio femenino desde el período colonial, en el cual sólo una voz -la de la madre Francisca Josefa del Castillo (1671-1742)- tuvo eco en la "literatura" virreinal.

\footnotetext{
${ }^{5}$ Algunos ejemplos de esta correspondencia femenina pueden verse en la obra de Tovar Pinzón (2004).
} 
Así mismo, fue la primera escritora civil de nuestra historia, y sus asuntos, en contraste con las ansiedades místicas de la monja tunjana, y de otras religiosas de tono menor, están referidos dentro de las tendencias de la época al amor filial, romántico, a la moral social, la historia y las costumbres nacionales (Carreño, 2012: 45). Dentro de sus publicaciones destacan el Ensayo sobre los deberes de los casados (las primeras ediciones fueron hechas en el exterior; sólo se encuentra en la Biblioteca Nacional de Colombia la quinta edición de 1857), que recibiría crédito sólo hasta la quinta edición realizada en Bogotá por la Imprenta de Francisco Torres Amaya en 1857. Este ensayo constituye una interesante aproximación a la mentalidad de la época en lo referente al matrimonio y a los roles masculinos y femeninos.

Carreño señala, además de su Tratado sobre economía doméstica para el uso de las madres de familia y de las amas de casa-como el anterior, una guía de comportamiento-, sus Poesías de una granadina (1853), varias biografías breves (la de su padre, reconocida como una de las piezas ejemplares del género en Colombia, la de su hermano José, la del doctor Vicente Azuero y de su primo hermano, el escritor Luis Vargas Tejada) y una autobiografía redactada poco antes de morir. Por último, encontramos los Cuadros de la vida privada de algunos granadinos copiados al natural para instrucción y divertimento de los curiosos (1861), que corresponde a narraciones cortas donde se ilustran con precisión y amenidad trozos de la vida de diversos personajes colombianos, célebres unos y otros olvidados o ficticios.

Un caso representativo, pero de finales del siglo XIX, es el de Soledad Acosta de Samper (1833-1913). Autora de excepcionales dotes y bastante prolífica, se mostró como una de las defensoras de las nuevas opciones para la mujer en una monografía titulada Aptitud de la mujer para ejercer todas las profesiones y el periodismo en Hispanoamérica, presentada en un congreso pedagógico celebrado en 1882 (Luna \& Villarreal, 1994: 67). Acosta de Samper figuró como directora de varias revistas femeninas entre los años de 1878 a 1881, siendo la más notable La Mujer (1878-1881). Otras, como La Caridad (1864-1882), El Iris (1866-1868), El Rocío (1872-1875), La Familia (1884-1885) y La Guirnalda (1873-1874), estimularon la producción y la lectura de la literatura femenina (DeJong, 1995:142).

Plantea Voz Obeso (2004: 8) que en sus escritos y artículos periodísticos, que fueron múltiples, se percibe una mujer con temores, con afirmaciones de su ser femenino, ambivalente, y a quien asaltaba el miedo de romper con el imaginario religioso femenino, puesto que, por su sexo, debió cargar con muchos sufrimientos y pesares. Sin desconocer esta carga existencial, que manifestó en muchos de 
sus escritos, se percibe la otra faceta de su personalidad como lo fue su posición crítica ante una sociedad enclaustrante (razón por la que siempre recomendó a las mujeres la necesidad de la educación para sobrellevar su pesada existencia).

Estos hechos evidentemente permitieron que en casi todas las ciudades de Colombia donde las mujeres ejercían el quehacer literario fuera un modelo a seguir. Waldina Dávila de Ponce de León, en Neiva, Herminia Gómez Jaime de Abadía, en Tunja, Priscila Herrera de Núñez, en Riohacha, y Pomiana Camacho de Figueredo, en Bogotá, son las más sobresalientes. En cuanto a la ciudad de Cartagena, encontramos el caso de Eva Ceferina Verbel y Marea, quien se hizo conocer a través de la publicación de sus poemas en varios periódicos literarios. Recogió sus producciones en verso y prosa en Ensayos poéticos en dos series (1874). Señala DeJong (1995: 154) que, aunque es considerada más bien poeta, contribuyó a la narrativa con dos novelas: Soledad (1879) -ampliada más tarde, en 1983- y la La mujer, que apareció en la revista homónima y dirigida por Soledad Acosta de Samper entre marzo y junio de 1880 (1995: 154). Al terreno dramático aportó dos obras inéditas: El honor de un artesano (1869) y María (1869).

Hasta aquí entrevemos cómo lentamente las mujeres se van apropiando del ejercicio literario y periodístico -desde sus inicios constituido en un espacio dominado y manipulado por los hombres de la élite y los líderes políticos-: las mujeres producen conocimiento y propician debates. Muchas de las que se vieron privilegiadas con la educación y los recursos mostraron su capacidad para incursionar en el campo a través de temas como la patria, la religión, el amor, y participaron en una variedad de géneros literarios como la novela, el cuento, el ensayo, el teatro y la poesía.

\section{Entre notas para el manejo del hogar y opiniones críticas: Cartagena a comienzos del siglo $\mathrm{XX}$}

Desde las dos últimas décadas del siglo XIX, hasta las tres primeras del XX, Colombia estuvo bajo la hegemonía del partido conservador. La situación social de las mujeres prácticamente permaneció sin evolución: la fuerte presencia de la iglesia católica en la vida política y cotidiana del país habría de repercutir enormemente sobre su existencia. Esta alianza del Estado y la Iglesia, y su oposición a los partidos de corte liberal, se manifestaría en la refrendación de un modelo tipo de feminidad: la mujer cuya función primordial en la vida es la de ser esposa sumisa y madre perfecta, dedicándose únicamente a las tareas del ámbito doméstico (Wills, 2006: 93). 
La transición del siglo XIX al XX marcó una serie de cambios institucionales que pretendieron trastocar incluso la vida diaria de la población, para amoldarla a un orden de mayores controles. De acuerdo con Bravo Páez (2005), el sentido de sociedad que emana del ideal conservador, a diferencia del liberal -que había gobernado el país hasta 1885-, conserva las bases morales de la religión católica. La sociedad colombiana se constituyó así como una comunidad coordinada por un órgano como el Estado, encargado de proteger y estimular la misión moral y pedagógica de la Iglesia: la educación y la familia, encabezada por el papel de la mujer, pero vista como la madre fiel, ejemplo de sus hijos, orgullo de su esposo, sujeta por completo al hombre y al hogar.

Hasta entonces el Código Civil, por ejemplo, no contemplaba los derechos de las mujeres. Éstas no podían administrar sus bienes, ni aun su salario, y mucho menos contratar por sí mismas, aceptar herencias o adquirir alguna clase de compromisos económicos sin la autorización escrita de su marido. Se les prohibía, además, comparecer en juicio. El matrimonió se convirtió, por esta vía según plantea Wills (2006: 93)- en una forma de despojarlas de su patrimonio, e impedir que construyeran una independencia económica. En pocas palabras, esta mujer colombiana se encuadra dentro del esquema tradicional de una mujer ideal: hogareña y sumisa. Veamos una nota al respecto, presentada por el periódico El Porvenir en 1894:

La mujer casada se parece a la abeja, cuando veo a la madre laboriosa que no falta en su casa, atendiendo sus quehaceres y guardando la dulce miel de sus caricias para su esposo; una mujer alejada de la casa y de los hijos, retirada de sus obligaciones no puede hacer la felicidad de su hogar; si ella se entrega a charlas inútiles su hogar dejará de ser el lugar donde el esposo encuentra refugio cuando regresa cansado del trabajo. (AHC. El Porvenir, Cartagena, julio de 1894, p. 6).

La educación basaba la instrucción en conocimientos de costura, oficios manuales, lectura, enfermería y religiosidad, que conllevaban al desempeño de sus funciones "naturales" de madre y esposa, perpetuando una concepción de mujer como ser pasivo en la toma de decisiones sociales y familiares, destinada a servir al hombre y a reducir sus apariciones a la esfera de lo privado (Herrera, 1985: 331). La participación en sociedad se reducía a los papeles permitidos o asignados por el género. En otras palabras, a actividades de solidaridad e instituciones orientadas por párrocos de iglesia. La 
beneficencia, sin embargo, fue un espacio de socialización para las damas de la élite. Algunas mujeres que se dedicaban a estas obras aprovechaban la salida de sus casas para cobrar protagonismo en la ciudad. Entre otras tareas, ayudaban a los niños y niñas huérfanos, a las viudas, madres abandonadas y madres solteras. La Época registra lo siguiente:

Camila Walters y Ana Elena Núñez, encargadas para la formación de un Comité de señoras y señoritas, que procure la recolección de los fondos para contribuir a completar la suma que exige Ángel García para su venida a Colombia a atender la cura de los enfermos de lepra que se encuentran asilados en los Lazaretos de la República, se permiten invitar a las señoras y señoritas que a continuación se mencionan, a una reunión que se verificará el sábado 9 del presente mes a las 3 de las tarde en la casa habitación del señor doctor Manuel Núñez Ripoll (AHC. "La caridad de nuestras damas y la suerte de los leprosos", La Época, Cartagena, 2 de marzo de 1918).

Meses más tarde, una publicación en El Porvenir refiere:

Seguramente tendréis noticia de que algunas señoras, señoritas y caballeros de esta cristiana sociedad han constituido un centro de Acción Social cuya misión es trabajar en beneficio de la clase obrera, ayudándola a formar a sus hijos para la obra del bien de ellos y de la sociedad. Diez escuelas ha logrado ya fundar y organizar el mencionado Centro; escuelas tal ha visto la luz pública, que están funcionando los diferentes barrios y parroquias de este Municipio, que tiene crecido número de habitantes de los cuales viven en no menos lastimoso abandono. Pues ese abandono y esa miseria son los que se propone aliviar el Centro Cristiano de que hacemos parte.

Por la breve exposición que sobre esta materia trascendental ha visto la luz pública, os habréis enterado de las obras que por ahora nos proponemos realizar con la ayuda de Dios, de la sociedad y de las entidades oficiales que dignamente están a la cabeza de la administración Municipal de Cartagena [...] (AHC. "La Acción social católica y la Municipalidad de Cartagena", El Porvenir, Cartagena, 30 de mayo de 1919). 
Lo anterior nos permite entender cómo en el discurrir de estos años las mujeres no fueron estáticas, ni mucho menos asumieron una actitud pasiva. Atrás quedan concepciones originarias que las describen como seres proclives al desorden y a la pasión, débiles e incapaces para alcanzar soluciones y tomar decisiones. ${ }^{6}$. Por otro lado, entendemos la razón del por qué las publicaciones para mujeres que empezaron a circular en las ciudades de Colombia incluían temas como cuadros de costumbres, consejos para el buen manejo del hogar, noticias sobre tertulias, bailes y moda. Varias de las publicaciones de esta clase que aparecieron en Cartagena datan desde 1871: La Primavera (1871), La Lira (1872), La Floresta (1879), Los Ecos del Mar (1881), La Tertulia (1888), El Bolivarense (18891890), El Amigo de las damas (1889-1890), El Álbum (1890), entre otras. Algunas podían resultar de tipo periodístico, otras no tanto, por el contrario, más literarias y noticiosas, con la semejanza única de que eran exclusivas para las mujeres (Buenahora, 2001: 23-32).

Hay que aclarar que, aunque eran dirigidas por hombres, tales publicaciones contaron con el apoyo femenino, que, con el trascurrir del tiempo -y después de las insistentes críticas debido a la falta de interés por explotar sus capacidades para la creación literaria-, iniciaría la participación formal en la escritura. En su mayoría, todas estas publicaciones fueron realizadas por la imprenta de Hernández e Hijos en Cartagena (Buenahora, 2001: 29). Para la década del treinta del siglo XX, y antes de la victoria liberal, se intensificarían cada vez más los debates sobre la condición de las mujeres en la educación, el trabajo o la salud ${ }^{7}$. Hecho que se convierte en la entrada formal para que se les otorgue el derecho a disponer libremente de sus bienes, contraer autónomamente deudas y realizar otras transacciones financieras.

Mediante el Decreto del Ejecutivo 227 del 2 de febrero de 1933 se aprobó el derecho a la educación, bachillerato clásico y el acceso a la Universidad, y en 1936, mediante la reforma del artículo 8 del acto legislativo $\mathrm{N}^{\circ} 1$, las mujeres ganaron el derecho a ejercer cargos públicos. No obstante, tendrían que esperar hasta el año de 1954 para ejercer la plena ciudadanía, cuando el presidente Rojas Pinilla les concediera el voto sin restricciones de ninguna clase -la norma que

\footnotetext{
${ }^{6}$ Nos referimos a concepciones originarias, aquellas que arrancan de autores clásicos como Aristóteles, quien relegó a las mujeres a seres sin capacidad ni inteligencia para tomar decisiones, atribuyéndoles una supuesta inferioridad. Para justificarlo, argumentó que era "natural".

${ }^{7}$ Luna \& Villarreal (1994) plantean el caso de las conferencias interamericanas celebradas en Chile en 1923 y en Cuba en 1928, donde los debates se movieron en el campo de los derechos políticos, las condiciones de educación, salud y trabajo y la necesidad de una reforma moral.
} 
formalizó dicha participación fue la reforma plebiscitaria de 1957-. Esta coyuntura explica el aumento de la participación de las mujeres en el ejercicio intelectual de la escritura y el periodismo. Desde años atrás, además de contemplar la historia, algunas mujeres insistían en el papel revolucionario y transformador que cumplía la educación, rechazando al tiempo el papel de adorno o de objeto sexual.

Pese a este gran impulso, las pocas mujeres de las ciudades colombianas que incursionaron en los "nuevos" quehaceres, lo hicieron con cierto recelo, empleando pseudónimos para esconder su verdadera identidad. Un ejemplo es el caso mencionado de Eva Ceferina Verbel y Marea, quien utilizó como pseudónimo el nombre Flora del Campo.

\section{Publicaciones femeninas durante la República liberal (Pie- drahita, 2008: 9) ${ }^{8}$}

\begin{tabular}{|c|c|c|c|c|c|}
\hline Revistas & Dirección & Ubicación & Periodicidad & Inicio & Termina \\
\hline $\begin{array}{c}\text { Agitación } \\
\text { femenina }\end{array}$ & Ofelia Uribe & Bogotá & Mensual & oct-44 & oct-46 \\
\hline Aurora & $\begin{array}{c}\text { Alicia Harker } \\
\text { de Carreño }\end{array}$ & $\begin{array}{c}\text { Bucara- } \\
\text { manga }\end{array}$ & Mensual & mar-41 & dic-43 \\
\hline $\begin{array}{c}\text { Ateneo } \\
\text { femenino }\end{array}$ & Inés Álvarez & Bogotá & Bimensual & nov-40 & ago-43 \\
\hline $\begin{array}{c}\text { Revista } \\
\text { femenina }\end{array}$ & Tulia Restrepo & Medellín & n.a & oct-38 & nov-41 \\
\hline $\begin{array}{c}\text { Hogary } \\
\text { patria }\end{array}$ & $\begin{array}{c}\text { Georgina } \\
\text { Fletcher }\end{array}$ & Bogotá & Quincenal & ene-35 & n.a \\
\hline $\begin{array}{c}\text { Heraldo } \\
\text { femenino }\end{array}$ & Tulia Marmolejo & Bogotá & Mensual & feb-32 & feb-37 \\
\hline $\begin{array}{c}\text { Letras } y \\
\text { encajes }\end{array}$ & $\begin{array}{c}\text { Teresa } \\
\text { Santamaría }\end{array}$ & Medellín & Mensual & ago-26 & sep-59 \\
\hline
\end{tabular}

Por medio del envío de cartas relacionadas con quejas -que irrumpían con la moral y la tranquilidad social de los habitantes-, algunas mujeres comenzaron silenciosamente un ejercicio periodístico que significó una participación en la opinión pública. Para ese entonces, la sociedad veía en este tipo de actividades no sólo el abandono, sino el mal cumplimiento de las obligaciones domesticas y familiares, y que urgía una sanción. La prensa definía enfáticamente que una "buena mujer" no necesitaba de la calle para vivir, que en el interior de la casa podía desarrollar todas las virtudes femeninas cumpliendo

\footnotetext{
${ }^{8}$ Muchas de estas revistas fueron dirigidas por mujeres y para mujeres, cuyo objetivo social era la reivindicación de la mujer dentro de los espacios políticos y ciudadanos.
} 
con las "tres fases de la vida: hija, esposa y madre" (AHC. La Patria, Cartagena, 20 de noviembre de 1920, p. 2).

Para los antecedentes del caso que nos hemos propuesto estudiar, encontramos a Concepción Jiménez de Araujo (1852-1929), quien publicó varios escritos bajo el seudónimo de Mary Faith. Este hecho no es de extrañar, pues su esposo, Antonio Araujo, era dueño del periódico El Porvenir. Varias de sus publicaciones, al igual que las de otras mujeres, debieron estar a veces a la sombra o tutela de sus maridos, de otros hombres, e inclusive benefactores. Tal participación, sin embargo, es clave para entender la expansión del periodismo en todo el territorio colombiano.

\section{La página de la Junta Cívica Femenina de Cartagena en la década de los cuarenta}

Entre sus columnas, el periódico El Fígaro, de Cartagena, implementó la página femenina. Es allí donde algunas mujeres de la ciudad comienzan a escribir conjuntamente con una variopinta de temas como la moda y la religión, pero también redactan consejos, relatos, noticias, opiniones y críticas sobre problemas de la ciudad. El viernes 26 de julio de 1940, El Fígaro expresa la cordial bienvenida a las mujeres intelectuales de la ciudad:

Con el mayor gusto cedemos esta parcela de nuestra "Página Femenina" a todas aquellas distinguidas amigas que se ejercitan en la vida intelectual y que entre nosotros se están abriendo paso por su clara inteligencia, su gran vocación para la literatura y su permanente inquietud por las cosas del espíritu. Toca hoy el turno a nuestra inteligente colaboradora, señorita Judith Porto Calvo, quien con suma gentileza ha correspondido a nuestra atenta invitación a colaborar en esta página. Recomendamos, el interesante artículo de la señorita Porto por lo exquisitamente escrito, por lo interesante del tema y por la gran erudición que revela la joven escritora en cuestiones tan importantes y de gran actualidad entre nosotros, como son todos los temas que se refieren a cuestiones de arte (6)

Muchos de los consejos y relatos publicados durante los meses que circuló la "Página Femenina" iban encaminados al "deber ser" de las mujeres. El lunes 8 de septiembre de 1941, por ejemplo, una nota titulada "La mujer y la sumisión", alude a ello: 
Madre: -La santa misión te facilitará el cumplimiento de tu deber principal: formar cristianamente a generación de mañana a todos tus hijos a la santa misión. Habrá un catecismo especial para los niños. ¿Todos hijos están bautizados? ¿Los que han cumplido 7 años han hecho la primera comunión?

Esposa: -La santa misión te hace reflexionar sobre tu obligación de vivir conforme a la ley del señor en el matrimonio. Conoce tu esposo de la necesidad de asistir a la santa misión. ¿Conoces hogares formados sin la bendición de la iglesia contra ley del señor? Aconseja el matrimonio y defiéndelo siempre.

Ama de la casa: -La santa misión es para todos, la sirvienta, la cocinera, la lavandera, el muchacho mandadero. Todas tienen el alma de salvar. Procura que todos ellos asistan a la santa misión.

Mujer Cristiana: -Tú debes ser la reina del hogar y por eso: VEN A LA MISION (AHC. "Culto Católico", El Fígaro, Cartagena, 8 de septiembre de 1941).

No obstante, conscientes de lo que podía significar el "deber ser" que se les atribuía para el futuro de sus hijos e hijas, se desempeñaron desde un rol público ante la visibilidad que se les quería negar. Llama la atención el cambio que se produce meses después en los contenidos de esta página, y del nombre también. Ahora bajo el sello de la Junta Cívica Femenina de Cartagena se incluyen temas de opinión y crítica. La Junta Cívica de Cartagena desde 1944 se constituyó en una institución que trabajó tesoneramente en el beneficio de la ciudad, y secundó un movimiento para impedir que la ciudad se obstruyera de problemas, entre ellos el relacionado con el cierre del viceconsulado de los Estados Unidos. El 27 de septiembre de 1948, con una comunicación expedida al Presidente de la República por parte de la directora Josefina Tono de Covo, la Junta deja entrever esta situación:

Extrañadas con la determinación de eliminar en Cartagena el viceconsulado americano, le pedimos respetuosamente intervengáis con vuestra poderosa influencia a fin de evitar esta medida que ocasionaría graves perjuicios a nuestra ciudad. Sean los motivos que este gobierno haya tenido para esto, pero es lo cierto que de efectuarse, dejará a esta ciudad no solo en un plano 
de inferioridad con respecto al resto del país, siendo el puerto oficial de la república y el primero en calidad, sino en constantes dificultades para los pasajeros que, obligadamente tendrían que ir a Barranquilla a resolver pasaportes, sino también para el zarpe de los buques pertenecientes a esa nación.

Seria nuestro deseo, como creemos que así mismo lo sea de toda la ciudad, si usted lo cree conveniente, que el gobernador de Bolívar uniera su voz a la de las demás entidades para pedir que sea revocada esta orden que tantos prejuicios acarrearía al puerto (AHC. "La Junta Cívica Femenina interviene para impedir el cierre del Consulado Americano", El Fígaro, Cartagena, 27 de septiembre de 1948).

La publicación del 30 de agosto de 1940, respecto al derecho del voto femenino, deja ver opiniones sobre esta situación (para el periodo aquí trabajado las mujeres todavía no ejercían su plena condición de ciudadanas):

-Doña Tulia Martínez de Azuero dice:

Me seduce la encuesta, pues ella contribuye a aclarar un poco el tema, desde hace algún tiempo discutido, sobre si la mujer puede o no, intervenir en las lides políticas. En mi consideración, la mujer Colombiana haría un papel desairado a una urna de votación el día de la jolgorio eleccionario [sic]. Su formación espiritual, hecha más bien para los temas dulces e alternativos de la lucha política, está indicando que es en la casa, en donde se está su más alta misión. Embelleciendo esa vida es como hacemos obra constructiva. Allí educamos nuestros hijos para que mañana, al fin hombres sigan opinando sobre cual sistema de gobierno se acomoda mejor a la de nuestro pueblo [sic]. Tiene para mí mayor emoción poética un almohadón que levantar una bandera y emitir el voto (AHC. "La Mujer Cartagenera...", El Fígaro, Cartagena, 30 de Agosto de 1940).

Estas consideraciones finales de una mujer arraigada al sistema patriarcal construyen un carácter que se pliega se suprime a todas los efectos, a los sistemas y denominaciones discursivas mediante los actos de habla. Facilita un discurso afable en el cual queda en evidencia que el sistema patriarcal no necesita ser un sistema represivo en todos los tiempos, aun menos en la casa, cuando es 
la misma mujer quien se siente con los derechos suficientes para suprimir, en un caso complejo, su propio modo de expresión vital.

-Señora doña Rosa Franco:

No soy partidaria del voto de la mujer ya que entre nosotras la política es una cosa muy ruin, y a nosotras nos corresponde una misión superior (Ibíd.).

El fracaso de una educación moderna e incluyente puede derivar en manifestaciones que sistematicen un dogma y lo hagan parecer cotidiano. Es decir, que lo naturalicen como algo normal; pero que a todas luces demuestra la influencia de la teología en la adquisición de los discursos narrativos de la mujer frente al derecho al voto y su libertad. Se ve coaptada a ver en el voto un "fin ruin", y como una "misión superior", el ser madre, esposa y hermana. Esto se debe, por supuesto, a los conceptos masculinos que dominan la sociedad y bajo los que la mujer no se ve participando. Avatares de por si bruscos para sus "necesidades":

-Señorita doña Cecilia Vélez:

No soy partidaria del voto femenino en este país ya que considero que nuestra misión debe ser destinada a lo del hombre [sic] para lograr el equilibrio capaz de hacer la felicidad de toda la sociedad. Sí, el hombre desde toda la historia se ha dedicado a la política. Mal encuentro que nosotros entremos a esos predios prohibidos (Ibíd.).

En la situación anterior observamos que la prohibición no parte de la subjetividad de la mujer. Esta subordinación parte de la represión del sistema patriarcal que ha surgido en el seno de la sociedad como un juez que facilita la dominación de la subjetividad femenina. De esta forma acalla mediante el discurso, incluso de las mismas mujeres, cualquier injerencia de subversión. En los tópicos narrativos que involucran la interioridad femenina hacia la libertad, su carácter libre se ve interrumpido por la sumisión a la tradición. De pleno surge el dogma teológico para salvaguardar el orden establecido de la subjetividad femenina.

-Señora Raquel del Real Torres:

La mujer tiene tantos derechos y obligaciones para la república como el hombre. Ella es la que da a la nación sus hijos y nadie más que ella está en el deber de opinar por el bienestar de Colombia que es el de todos los que 
nacen en ella. Si vota el borracho, el holgazán, el ladrón por qué no, nosotras (Ibíd.).

En el discurso anterior prima el acto de habla de la libertad como inclusión: se determina una subjetividad; se toma una posición frente a la historia.

-Señora doña Gloria Almiaro:

A si [sic] como los "maricelitas" repudian a los "centenaritas" yo repudio igualmente a la mujer pegada a la tradición que se pasa la vida bordando y rezando (Ibíd.).

El discurso de la acción. La mujer aborda su subjetividad con valores que dependen de sí misma, de su propia construcción frente a la sociedad; no sólo de su inicio subjetivo como discurso. No sólo del comienzo de la reparación o deconstrucción de su historia o de la tradición, sino de frente al inicio de un nuevo destino hacia la sociedad que la mantiene oprimida.

-Señora doña Aura Herrera Anzoátegui:

Doy mi voz y aplauso a la brillante idea del voto femenino por considerar que hay en ella un nuevo campo en donde poder esparcir sus cultas semillas la mujer Colombiana, acabando una vez más con esa triste idea de que la mujer carece de inteligencia superior al hombre. Ya se terminará con los egoísmos masculinos y se verá a la mujer compartir con satisfacción los destinos de la patria (Ibíd.).

Podemos observar aquí la manifestación de un sujeto político femenino en toda su dimensión. Si analizamos su respuesta, encontraremos actos de habla heterogéneos, sin una coma de duda frente al poder, al discurso, la historia, la política y la naturalización del sistema patriarcal que lo tenía en el borde, siempre atrás, dejando que su feminidad se diluyera en construcciones que conducían por el sendero del hermetismo, la sumisión y la desconfianza. "Ya no más" parece ser la consigna subversiva, el triunfo imaginativo de la libertad de la mujer para la consecución del poder en la sociedad.

Algunas de estas opiniones nos permiten entender cómo para la década del cuarenta aun predominaba en la sociedad un pensamiento tradicionalista, donde seguir con la condición de madres y reproductoras del hogar era un discurso transmitido por las mismas mujeres todavía vinculadas a una ideología patriarcal y católica. Pero 
también podemos ver cómo otras mujeres buscaban romper con las ataduras, pronunciándose y convirtiendo el tema del voto femenino en un aspecto propio que, como muchos, era todavía exclusivo de los hombres. La prensa aparece así como una nueva y posible forma de difusión del pensamiento femenino. Debemos tener en cuenta, además, que estas voces de reclamo ayudaron a las mujeres de la élite a ser visibles

La "Página Femenina”, o de la "Junta Cívica Femenina de Cartagena", impulsaron un eficaz centro de conciencia para las mujeres cartageneras. Si bien algunos de sus escritos estaban encaminados hacia el buen comportamiento y la belleza, también otros abrieron un espacio a la opinión. Más tarde, cuando se funda el periódico El Universal, hacía 1948, diversas mujeres tendrán una variada muestra de temas y críticas, no sólo referentes a su situación como mujeres, sino a las de las comunidades barriales.

\section{Las mujeres y las artes en Colombia: hacia un nuevo despertar creativo}

Si escribir fue difícil para las mujeres, pintar, esculpir y componer música ${ }^{9}$, lo fue aún más. Numerosas mujeres artistas pasaron desapercibidas, o fueron descubiertas tardíamente. Pero su participación ha estado siempre latente y ha sido bastante significativa, dando aportes fundamentales para el desarrollo del arte nacional. El trabajo adelantado por Serrano (1995) permite comprender cómo aquellas mujeres que incursionaron en el campo de las artes fueron probablemente un grupo numeroso durante la época colonial (pudieron haber colaborado en los talleres de pintores neogranadinos, o inclusive haber practicado la pintura en la reclusión doméstica. Serrano señala que, trascurrida la campaña independentisa, y tal vez gracias al ejemplo de valor que durante su transcurso dieron numerosas mujeres, muchas comenzaron a tomar ciertos riesgos, a emprender nuevos oficios, e incluso a figurar prominentemente en las primeras exposiciones artísticas que se celebraron en la nueva República.

Hacia 1841, con bordados y pinturas al óleo, algunas mujeres hicieron su entrada formal en las presentaciones públicas de arte. Destacan

\footnotetext{
${ }^{9}$ La historia del arte debe ser concebida como una visión general del mundo de las formas expresivas y de la evolución de los estilos, relacionada con las demás manifestaciones de la cultura, y como una selección ejemplar no sólo de autores y obras famosas, sino de fenómenos y obras significativas.
} 
especialmente con dos géneros pictóricos: la naturaleza muerta y el desnudo $^{10}$. En el primero, tenemos a la pintora Margarita Merizalde, con su obra "Flores de mano", expuesta en el año de 1846 -obra que se convirtió en un referente a seguir para muchas mujeres, dos años después, en la exposición de 1848-. El género pictórico de la naturaleza muerta llego a relacionarse en algunos casos con las virtudes más admiradas de la mujer, como la pureza, la dulzura y la espiritualidad.

Para el caso del desnudo, las obras de Blandina Petra y Olaya González dan apertura al género en Colombia. Un verdadero reto, puesto que los pintores masculinos no se habían atrevido a representar, o exponer públicamente, obras de este tipo. Serrano (1995: 103) explica que la actitud franca, y para nada prejuiciosa de estas artistas, permite medir la convicción, el entusiasmo y la seriedad del compromiso que algunas mujeres habían comenzado a asumir como pintoras.

Tendrían que pasar muchos años para que la mujer pudiera ejercer plenamente el quehacer artístico. En elsiglo XX, ya para la década de los cuarenta, entre tantas cosas que pasaron, los movimientos modernos se arraigaron finalmente, abriéndose paso a una producción artística en la cual el estilo es la consideración fundamental y la emancipación del individuo uno de sus más preciados objetivos. Al mismo tiempo, tiene lugar el recién instaurado Salón Nacional de Artistas -espacio que les brindó la posibilidad de competir con los hombres en materia de creatividad y talento-. La cita fue para todas las capitales del país, entre ellas Cartagena. El 20 de octubre de 1944, Antonio del Real Torres presenta para el periódico El Fígaro un balance sobre la cultura colombiana de aquellos días:

Los últimos años han sido de enorme utilidad para nuestra cultura. De esto no queda duda. Apartándonos un momento de todo lo que se refiera a libros de críticas, de novelas, de poesías, la pintura y la escultura han alcanzado un grado de altura admirable en Colombia. Sobre crítica quizá lo único digno sea la obra de Maya. Sobre novela, nada trascendental, si apenas los grandes trabajos de Ossorio Lizarazo, que se colocará, ya en el cenit de su especialidad, como el primero en este ramo

\footnotetext{
${ }^{10}$ La naturaleza muerta es el género más representativo de la imitación de la naturaleza de objetos inanimados, en general de la vida cotidiana, como frutas, flores, comida, utensilios de cocina, de mesa, libros, joyas etc. Se puede decir, que es el menos literario de todos los temas, mientras que el desnudo es un género artístico que consiste en la representación del cuerpo humano desnudo: es considerado una de las clasificaciones académicas de las obras de arte (Trujillo, 1999: 5).
} 
de la inteligencia. Sobre poesía no podemos citar nada. Los altos valores de la poemática colombiana nos han dado sus producciones viejas, ahora recogidas en volúmenes preciosos, pero ya conocidas. Los nuevos poetas, aun ensayan cada día formas y actitudes en el verso. Sólo en las arte plásticas se ha notado cambio; y se mira agitación permanente en su campo. De Bogotá, de Medellín, han salido sorpresas que constituyen pilastras encima de las cuales se sujeta el porvenir de la pintura y de la escultura de Colombia, ampliamente prometedor. En Manizales y Cali, también han surgido valores, menores en todo caso pero apuntando hacia primeros puestos ("El arte pictórico en Colombia", El Fígaro, Cartagena, 20 de octubre de 1944).

En 1891 se había fundado ya en Cartagena la escuela de Bellas Artes por Epifanio Garay: iniciativa del entonces presidente Rafael Núñez y de doña Concepción Jiménez de Araujo, de acuerdo con el Decreto 141 del 28 de abril de 1891. En los inicios del siglo XX esta escuela entró a formar parte de la Universidad de Cartagena y dejó de funcionar durante treinta años, hasta que, a mediados del siglo XX, bajo la gobernación de Eduardo Lemaitre (junto con su secretario Aurelio Martínez Canabal y la Secretaría de Educación Departamental), se hizo cargo de su regreso el Instituto Musical y de Bellas Artes, de acuerdo al Decreto 755 del 19 de diciembre de 1957. Las noticias no se hacen esperar en la ciudad y la prensa alude al aporte de las mujeres cartageneras a la feria del Arte:

A la gentil aceptación de la señorita Cecilia Armienta Jiménez de dictar una conferencia en la feria del arte, se añade la espontanea manifestación de la señorita Judith Porto Calvo de comentar las obras artísticas enviadas a dicha feria, y de dar un concierto de violín en día de la inauguración.

Judith Porto Calvo es una fina sensibilidad de buen gusto literario, [...] Polisón, quien en respuesta a la circular de la feria del Arte contesta plena delicadeza y espíritu en atenta carta de la cual destacamos los siguientes párrafos: "mucho les agradezco y con verdadero placer pondré mi pequeña contribución para el éxito de la feria del arte".

Igualmente a la señorita Ester Gómez Cáceres, en frases de estímulo y aliento para los organizadores de la feria 
del arte, da su respuesta afirmativa a la invitación que se le hiciera de enviar sus trabajos [...]. (AHC. "Aporte de la mujer Cartagenera a la feria del Arte", El Fígaro, Cartagena, 15 de julio de 1940).

Meses después, algunas informaciones venidas de la hermana ciudad de Barranquilla revelan que el resultado del primer premio de esta exposición fue ganado por el conocido escultor Carlos Reyes, con una magnífica obra tallada en madera. Igualmente, se informa que el segundo premio correspondió a la señorita Cecilia Porras, por su obra "Madre India," y que la primera mención honorifica le fue dada al señor Miguel Guerra, por su bello cuadro "Paisaje Balares". Estos tres últimos artistas son cartageneros, por lo que se les felicita (Cf. AHC. "Aporte de la mujer Cartagenera a la feria del Arte", El Fígaro, Cartagena, 15 de julio de 1940).

El ejemplo de Cecilia Porras (1920-1971) es bastante interesante, pues hace parte de una generación de creadores que irrumpió en el arte colombiano a mediados del siglo XX, sobresaliendo como creadora en la pintura, el diseño gráfico, la ilustración y la realización audiovisual. Porras, nacida en la década del veinte, aparece en el panorama artístico del país hacia 1945, al ganar una mención de honor en el Primer Salón de Artistas Costeños, celebrado en la Biblioteca Departamental de Barranquilla (cf. "Cecilia Porras: una maravilla desconocida", El Universal, Cartagena, 18 de octubre de 2009).

El siglo XX en Colombia corresponde así a un periodo donde el trabajo y la vida social femenina presentarían muchos cambios y rupturas. En este sentido, el hecho de darle continuidad a su estudio desde la historiografía permite visibilizar los procesos en los que se enmarcaron algunas mujeres, dejando el espacio de lo estrictamente doméstico. Artes y letras se constituyen ante todo en una vía de escape de una sociedad que negaba la participación pública de lo femenino. Hasta aquí hemos repasado, la historia de algunas mujeres que se debatieron entre el quehacer literario o artístico, relegando en algunos casos su "destino" -negándose a conformar una familiay buscando una originalidad creadora. Una historia a la que todavía le hace falta mucho por escribir. 


\section{Bibliografía}

\section{Fuentes primarias}

\section{El Fígaro:}

AHC. "Culto Católico". El Fígaro, Cartagena, 8 de septiembre de 1941. Tomo XIX.

AHC. "La Junta Cívica Femenina interviene para impedir el cierre del Consulado Americano". El Fígaro, Cartagena, 27 de septiembre de 1948.

AHC (AHC). "La mujer Cartagenera.... El Fígaro, Cartagena, 30 de agosto de 1940.Tomo XI.

AHC. "El arte pictórico en Colombia". El Fígaro, Cartagena, 20 de octubre de 1944

AHC. "Aporte de la mujer Cartagenera a la feria del Arte”. El Fígaro, Cartagena, 15 de julio 1940. Tomo IX.

El Porvenir:

AHC. El Porvenir, Cartagena, julio de 1894, p. 6.

AHC. "La Acción social católica y la Municipalidad de Cartagena”. El Porvenir, Cartagena, 30 de mayo de 1919.

La época:

AHC. "La caridad de nuestras damas y la suerte de los leprosos". La Época, Cartagena, 2 de marzo de 1918.

\section{El Universal:}

"Cecilia Porras: una maravilla desconocida", El Universal, Cartagena, 18 de Octubre de 2009.

\section{Fuentes secundarias}

Buenahora, G. (2001). Las publicaciones dirigidas al "bello sexo" y la educación femenina en Cartagena, 1871-1893. Trabajo de grado, Programa de Lingüística y Literatura, Cartagena, Universidad de Cartagena.

Carreño, A. (2012). “Josefa Acevedo de Gómez”, Biblioteca Virtual Luis Ángel Arango: http://www.banrepcultural.org/blaavirtual/biografias/ acevgome.htm [Consultado el 1 de abril de 2012]

DeJong, J. (1995). "Mujeres en la literatura del siglo XX". En Las mujeres en la historia de Colombia. Bogotá: Norma, vol. III, pp. 137-157.

Duby, G. \& Perrot, M. (1992). Las mujeres en la historia de occidente. Madrid: Taurus.

Herrera, M. (1985) "Las mujeres en la historia de la educación". En: Las mujeres en la historia de Colombia, II. Bogotá: Norma. 
Jaramillo, M. \& Osorio de Negret, B. (1995). "Escritoras colombianas del siglo XX". En Las mujeres en la historia de Colombia, III. Bogotá: Norma.

Lagunas, C. (1996) "Historia y Género. Algunas consideraciones sobre la historiografía feminista", La Aljaba, vol. I, n¹, Argentina, Universidad Nacional de Lujan.

Londoño, P. (1995). "Las publicaciones periódicas dirigidas a las mujer, 1858-1930". En Las mujeres en la historia de Colombia, II. Bogotá: Norma.

Luna, L. \& Villarreal, N. (1994). Movimiento de mujeres y participación política en Colombia, 1930-1991. Barcelona: Universidad de Barcelona.

Pacheco, E. (2008). "Espejos que dejan ver. Mujeres en las artes visuales latinoamericanas", Anuario № 6, Santiago de Chile, pp.321-324.

Perrot, M. (1997). Mujeres en la ciudad. Santiago de Chile: Andrés Bello.

Piedrahita, I. (2008). Mujer y publicaciones femeninas durante la época liberal. Trabajo de grado, Programa de Comunicación social, Universidad Javeriana, Bogotá, p. 9.

Postor, R. (1998) "Asimetría general y representación de género". En Fernández, J. Género y sociedad. Madrid: Pirámide, pp. 207-236.

Rivera, L. (2007). “La construcción del deber ser femenino y los periódicos para mujeres en México durante la primera mitad del siglo XIX", Ciencia Nicolaita, ${ }^{\circ} 48$ (Agosto), Michoacán, Universidad de Michoacana de San Nicolás de Hidalgo, pp.5-17.

Serrano, E. (1995). "Las mujeres y el arte en Colombia”. En Las mujeres en la historia de Colombia. Bogotá: Norma, pp. 256-273.

Tovar Pinzón, H. (2004). La batalla de los sentidos. Infidelidad, adulterio, concubinato a fines de la colonia. Bogotá: Fondo de Cultura Cafetero.

Trujillo, M. (1999). Las artes plásticas en Cartagena en el siglo XX. Cartagena: Universidad Jorge Tadeo Lozano.

Vidales, C. (2012). "Escritoras y periodistas colombianas durante el siglo XIX", La rana dorada: http://hem.bredband.net/rivvid/carlos/ mujeres.htm [Consultado el 03 del abril del 2012] 
